\section{Expensive, Harmful Policies that Don't Work or How Juvenile Sexual Offending is Addressed in the U.S.}

\author{
Elizabeth J. Letourneau ${ }^{1} \&$ Michael F. Caldwell ${ }^{2}$ \\ ${ }^{1}$ Johns Hopkins Bloomberg School of Public Health \& ${ }^{2}$ University of Wisconsin, Madison
}

\section{Abstract}

In this policy paper we briefly review the historical predecessors of modern sex crime legislation. We then review modern policies, focusing on those that have been applied to youth who have sexually offended and for which there is at least some empirical evaluation. These include sex offender civil commitment, registration and public notification. None of the existing research validates the use of these strategies with juveniles and indeed there is growing evidence of harm. As such, we recommend that policies be revised to either exclude juveniles altogether or to mitigate the negative effects of policies when applied to juveniles.

\section{Keywords}

Sexually abusive behavior, sexually abusive youth, juvenile sexual offenders, juvenile sexual offending, sexual offense treatment, juvenile public policy, juvenile, sex offender registration

Punishing youth for and suppressing their sexual behaviors is neither new nor rare. However, relative to other democratic countries, particularly Scandinavian countries, the United States approaches the suppression of adolescent sexuality with particularly aggressive zeal. Adolescents are considered incapable of providing consent for sex until they reach a given state's age of consent (typically between 16 and 18 years of age) and these prohibitions frequently include sexual activity with consenting age mates (Sutherland, K., 2003). Moreover, since the early 1980's, the U.S. government has actively promoted and funded abstinence-only-until-marriage sexual education curricula, despite evidence that such programming leaves youth at greater risk for unprotected sex (Dailard, 2006).

The U.S. also takes a heavier hand toward juvenile delinquency than is true of most other democratic countries, only recently prohibiting applications of the death penalty and life imprisonment in juvenile cases, broadly permitting the prosecution of minors as adults, and essentially failing to set a lower age below which children are considered not culpable of delinquent or criminal offending (i.e., some states prosecute children as young as 6 years of age; Muncie, 2008).

Perhaps not surprisingly, the U.S. sets itself apart from other democracies to an even greater extent with policies that conflate adolescent sexual behavior and juvenile delinquency - that is, with policies that respond to a broad range of adolescent sexual behavior as juvenile sexual offending. Although the U.S. is not alone in subjecting juveniles who have sexually offended to far-reaching policies (e.g., at least two Australian states curtail the future career options of youth who have sexually offended), there simply is no other democratic nation in which youth adjudicated as minors for sexual offenses face penalties as severe as those found in the U.S. For this reason, the present policy review limits itself to modern U.S. polices. But first, we begin with some history.

\section{U.S. Sex Crime Legislation: 1880s-1980s}

As described previously (Letourneau \& Levenson, 2010), the U.S. has experienced three waves of sex crime legislation over the past 100 or so years. The first wave spanned from the late 1800's to the end other criminals, and the mentally ill or incapacitated were subjected to indefinite institutionalization and sterilization. These policies were jointly influenced by the fields of sexology and eugenics (Ordover, 2003). Specifically, sexologists promoted the view that even minor forms of sexual misbehavior predicted future sexual violence and homicide (Jenkins, 1998), whereas eugenicists promoted the view that criminal behavior was genetically determined (Ordover, 2003). In combination, these fields shaped a view of sexual offending as intractable, resistant to change, and escalating, convincing policy makers to enact extreme interventions to limit society's immediate exposure to danger from an offender (via institutionalization) and future exposure to danger from an offender's offspring (via forced sterilization). When eugenics became associated with Nazism, forced sterilization of U.S. citizens fell out of favor (Ordover, 2003) and in 1942 its use for punishment was ruled unconstitutional (Skinner v. Oklahoma), although its use for eugenics continued for four more decades. Of relevance to this discussion, sterilizations programs often targeted children, many of whom resided in congregate care facilities such as prisons and reform schools (Owens-Adair, 1922; Silver, 2003-2004). Take for example the case of John $\mathrm{H}$. who at the age of 17, was sterilized while imprisoned in an Oregon State Penitentiary (Owens-Adair, 1922). The reason given for his sterilization was "allowing other prisoners to commit sodomy on his person." The operation was considered a success by the warden, who noted that "at least we have had no further trouble with the boy" (p. 145). These and similar anecdotes were considered to support the positive effects of sterilof World War II, during which time sex offenders, ization, which were heavily promoted by the book's author. Overlooking the homophobic response to male-on-male sodomy for a moment, one wonders just how consensual these experiences were from the perspective of a 17-year-old boy housed with many older, and possibly more violent, prisoners.

The subsequent two waves of sex crime legislation can each be attributed, in part, to specific, highly publicized and gruesome sex crimes that helped fan fears of sex crime epidemics. In Wave II, which spanned, approximately, from the late 1930s through the late 1960s, the public's fears about sex offenders were inflamed following publicity of horrendous crimes committed by Albert Fish against children in the late 1930s (Schwartz, 2011). Fish's crimes and the resulting media also coincided with the rise of forensic psychiatry, which sought to increase its relevance to and influence with the courts by promoting certain forensics-based interventions. Among these was the treatment of so-called "sexual psychopaths" whom, it was argued, required psychiatric intervention rather than incarceration (Lave, 2009; see also Sutherland, E. H., 1950¹). Between 1937 and 1967, 26 states and the District of Columbia passed so-called sexual psychopath laws, in which sex offenders who were deemed mentally ill and lacking the power to control their sexual impulses could be institutionalized prior to and in lieu of incarceration (for an in-depth review, see Lave, 2009). Pre-incarceration commitment policies fell out of favor relatively quickly when it became clear that the criteria for distinguishing between sexual psychopaths (who needed help) and other sex offenders (who needed punishment) were flawed, and because treatment was viewed as ineffective (Lave, 2009). As in Wave I, juveniles were also subjected to the indefinite commitment policies of Wave II, despite the fact that these policies were predicated on fears about adult sex offenders. Consider the case of Elvry Stoneham. At 12 years of age, he was made a ward of the juvenile court because he was in danger of "leading a lewd and dissolute life" (In re Stoneham, 232 Cal. App. 2d 337). At 17 years of age and following a series of unspecified parole violations, he was returned to the California Youth Authority, which found him to be a mentally disordered sex offender, a prerequisite to involuntary commitment. According to Mr. Stoneham's petition for relief from commitment, he had never been convicted of an actual sexual offense.

1 One hesitates to cite Sutherland as an authority on sex crime policy when, in this same text, he dismisses the possibility of forcible rape as "practically impossible unless the female has been rendered practically unconscious by drugs or injury" (p. 545), an argument eerily similar to recent controversies within the U.S. Republican political party about the likelihood of pregnancy following "legitimate rape" (e.g., see for brief overview the Wikipedia entry at http://en.wikipedia.org/wiki/Rape_ and_pregnancy_controversies_in_United_States_elections,_2012). 


\section{Modern U.S. Sex Crime Legislation: 1990s-Present}

Wave III of sex crime legislation is ongoing and dates to the late 1980s when the public's fears about sex offenders resurfaced, fanned again by sensational media coverage of exceptional cases and belief in a sex crime epidemic. Numerous policies were enacted at local, state and federal levels, including post-incarceration civil commitment for so-called "sexually violent predators" (SVP), sex offender registration, and public notification. In addition to these policies, states and local jurisdictions have attached numerous collateral legal consequences to registration requirements, including residency and employment restrictions, GPS monitoring, and others (Lester, 2006; Levenson \& D'Amora, 2007). However, for purposes of this paper we restrict review to those policies with at least one published study evaluating policy effects on juveniles, which (as detailed later) include civil commitment, registration, and notification.

Civil commitment. Modern civil commitment laws date to the horrific case of Earl Shriner who made no secret of his intention to torture and mutilate children upon his release from the Washington State prison in 1987 where he was confined due to his prior abduction and assault of two teenage girls. Prior to this conviction, he had served 10 years in a psychiatric hospital for the murder of a teenage girl and was also known to have choked and assaulted a younger girl. Despite efforts to keep him committed under existing "imminent danger" mental health civil commitment policies, Mr. Shriner was released and subsequently raped, mutilated, and left for dead a 7-year-old boy (LaFond, 2005). The boy did not die and Shriner was rearrested. However, the child's parents and community members were outraged that the state had been unable to prevent this crime from happening in the first place and a grassroots organization urged the governor to develop new policies to address this gap in community safety. In 1990, Washington State passed the first modern sex offender civil commitment policy, which also included components of sex offender registration and public notification ${ }^{2}$. Since then, a total of 21 states, the District of Columbia, and the federal government have enacted civil commitment policies targeting the "worst of the worst," or so-called "sexually violent predators" (National District Attorneys Association, 2012). Policies vary but typically require that, prior to release from confinement, convicted sex offenders undergo evaluation to determine whether they meet a state's criteria of being both mentally disordered and likely to commit violent sexual crimes. If evaluated as such, legal proceedings ensue that will make the final determination as to whether or not the offender will

2 Several states (e.g., California, Minnesota) retained their origina sexual psychopath laws, but adopted an updated SVP policy. be committed. While committed, offenders are to receive specialized treatment until such time as they are considered to pose little threat to community safety. Commitment is indefinite and release is rare. For example, an audit of Minnesota's civil commitment program, which had been operating for 10 years, revealed that not a single offender had ever been discharged from treatment (Office of the Legislative Auditor, State of MN, 2011).

In many states, youth adjudicated delinquent for sexual offenses are or can be evaluated for civil commitment. A recent example is the case of Thomas S, who, at the age of 10 , was adjudicated delinquent as a minor for sexually abusing a younger relative. From ages 12 to 17, he was incarcerated in a South Carolina juvenile detention facility, and when, in 2008, he was finally considered eligible for release by the juvenile parole board, he was automatically evaluated for civil commitment per that state's SVP policy. Despite having just one known victim whom he molested when he himself was very young, Thomas was found to meet criteria as a SVP and subjected to a jury trial to determine commitment. At that initial trial, a representative of the civil commitment facility itself argued against commitment, fearing among other things that Thomas would be targeted by the older, more violent offenders housed in that facility and also because the representative did not feel Thomas' profile fit that of an SVP. Nevertheless, the jury voted to commit. Each year thereafter, the civil commitment facility supported Thomas' petition for release, and in each of three subsequent trials juries voted to continue his commitment. Eventually, Thomas' attorney successfully argued to the state supreme court that he should never have been committed in the first place, due to introduction of non-expert testimony at the first commitment hearing. By the time his release was ordered by the state supreme court in 2013, Thomas had spent five years in the locked, high-security civil commitment facility. Of note, South Carolina's cost for civil commitment averages (US) $\$ 63,000$ per year, per patient (Smith, 2010), for a total of $\$ 315,000$ across Thomas' five years of commitment. Estimating the cost of his prior 5-year juvenile incarceration as approximately $\$ 75,000$ (based on $\$ 15,000 /$ year/ inmate, the going rate for that state's adult incarceration; see http://www.doc.sc.gov/pubweb/faqs.jsp), then this state "invested" approximately $\$ 400,000$ in Thomas. This amount, however, likely underestimates true expenses, given that it does not include any legal costs related to arrest, prosecution, probation, or the juried and non-juried trials. Predictably, Thomas' childhood was characterized by parental and non-parental abuse and neglect. Had the state provided Thomas and his family with evidence-based prevention programming - including even several of the costliest prevention programs - it would have spent twenty times less than it did on his incarceration and commitment alone ${ }^{3}$.

Sex offender registration and notification. Sex offender registration and notification were components of the Washington State law but, unlike its civil commitment policy, registration and notification were not initially widely adopted by other states. This changed in the mid-1990s when for the first time the U.S. federal government required states to create sex offender registries and, shortly thereafter, required states to provide information on sex offenders to the public. These statues carry the names of the victims in whose memory they were created. In 1989, Jacob Wetterling was abducted by a masked gunman and has never been seen since. His mother founded the Jacob Wetterling Foundation (now the Jacob Wetterling Resource Center), which among other activities urged the state to develop sex offender registration policies on the reasonable assumption that the gunman had likely offended before. The state did so, and the policy was taken up at the federal level as the Jacob Wetterling Crimes Against Children and Sexually Violent Offender Registration Act (enacted under the federal Violent Crime Control and Law Enforcement Act of 1994). The federal Wetterling Act established registration requirements for all states and other jurisdictions and permitted public notification. In 1994, Megan Kanka was lured into the nearby home of a convicted sex offender who then raped and murdered her. Convinced that they could have protected their daughter had they known about the offender's presence in their neighborhood, Megan's parents petitioned the state to established a community notification policy in which community members are notified when a convicted sex offender moves into the community. The federal version of "Megan's Law" was enacted in 1996 and amended the Wetterling Act by mandating public notification requirements.

As originally defined by these and related federal statutes, states had considerable leeway in crafting their registration and notification policies, including whether or not to include juveniles. However, the more recent Adam Walsh Act of 2006 (AWA) was developed and implemented specifically to reduce between-state policy variations and, for the first time, required the registration and notification of juveniles adjudicated delinquent by virtue of certain sex crimes. The public notification requirement elicited strong negative reactions from enough quarters that it was eventually dropped from the Act (Docket No. OAG 134; AG Order No.

3 For example, given Thomas' parents' poverty and substance abuse disorders, early primary prevention/family strengthening strategies such as Nurse Family Partnership for Low Income Women $(\$ 9,118)$ and Early Childhood Education for Low Income 3- and 4-Year Olds $(\$ 7,301)$ might have been worthwhile; given his later school difficulties and delinquency, Multisystemic Therapy $(\$ 5,681)$ might have been helpful. Together, these programs sum to $\$ 22,100$ (Aos, Lieb, Mayfield, Miller, \& Pennucci, 2004). 
3150-2010), but juveniles 14 years of age and older who are convicted of certain sexual offenses must still register for 25 years or life, depending upon their offense and offense history. States that refuse to comply with this or other aspects of AWA are penalized by the loss of certain federal funds. A recent review of state policies indicated that 35 states have juvenile registration requirements (not infrequently for life) and 25 states include juvenile registrants information in online registries (Pitman \& Nguyen, 2011), demonstrating that the AWA has significantly increased the scope of juvenile registration (Chaffin, 2008).

Because registration and notification of juveniles is both recent and now commonplace, anecdotes about youth affected by these policies abound. One case that was widely publicized by the New York Times involved "Johnnie" (Jones, 2007). When Johnnie was 11 years old he molested his younger sister. Unsure of what to do, his mother turned to law enforcement for help. They arrested Johnnie, and he was adjudicated and placed in specialized residential sex offender treatment for 16 months Upon his return to family care, his information as a registered sex offender was made public on his state's online registry. Johnnie's first suicide attempt occurred two weeks later, after classmates began to harass him based on his registration status. $\mathrm{He}$ made at least two more suicide attempts, shuttled between family and non-family care, and had to switch schools repeatedly following ongoing harassment.

The costs of registration and notification have not been well documented. However, prior to implementing the Adam Walsh Act registration and notification requirements, several states attempted to quantify these costs, in an effort to determine whether the cost of complying with the Act exceeded the potential loss in federal funds tied to noncompliance. Estimates varied widely. For example, an Ohio fiscal impact evaluation indicated that enacting the Act's registration and notification requirements would result in one-time expenditures of $\$ 475,000$ and annual expenditures of $\$ 85,000$, solely to update and maintain the registry. It was also assumed that unspecified but substantial increases would occur in legal and incarceration expenditures related to implementation $\left(127^{\text {th }}\right.$ General Assembly of Ohio, 2007). By comparison, a Virginia fiscal impact statement that included estimated increases in some legal and incarceration costs estimated an outlay of nearly $\$ 12,500,000$ during the first year of implementation, and nearly $\$ 9,000,000$ each year thereafter (Department of Planning and Budget, 2008). What is less clear from these and other fiscal impact statements is the per-person cost of registration and notification. Because the Adam Walsh Act increased the frequency of mandatory in-person re-registration, the amount of information collected, the procedures required for verifying the information, the dura- tion of registration requirements, the types of offenses that trigger registration, and the penalties for registration errors and omissions, now to include a minimum one year of incarceration for the first infraction, the per-person costs of the Act's registration and notification requirements are substantial. We argue that these additional costs, though poorly documented, very likely exceed $\$ 9,000$ per-person, which is the average cost of evidence-based treatment programs targeting juveniles who have sexually offended (Aos, Phipps, Barnoski, \& Lieb, 2001).

\section{- Do Modern Policies Improve Community Safety?}

Modern sex crime policies have, at their core, the aim of reducing the risk of sexual recidivism posed by known offenders. Civil commitment policies aim to reduce recidivism risk by extending the incapacitation and treatment of offenders until such time as they might safely be returned to their communities. Registration policies aim to reduce recidivism by making it easier for law enforcement to scrutinize sex offenders. Notification policies aim to reduce recidivism by empowering regular citizens to scrutinize offenders and report suspicious behaviors. Additionally, it is hoped offenders view registration and notification as increasing the risks of getting caught should they reoffend, thus altering their own personal risk-benefits evaluation of future offending.

The success of these policies rests, in no small part, on the accurate identification of high risk offenders. Additionally, focusing expensive interventions on high risk youth also improves the likelihood of cost effectiveness. Thus, accurate recidivism risk prediction is a necessity. Yet recidivism risk prediction for juveniles is complicated by numerous factors. First and foremost, juvenile sexual recidivism has very low base rates: the fact is that the vast majority of youth adjudicated for a sexual offense will not sexually reoffend, even across decades-long follow-up (e.g., Caldwell, 2010; Letourneau \& Armstrong, 2008; Worling, Litteljohn, \& Bookalam, 2010; Zimring, Jennings, Piquero, \& Hays, 2009). Furthermore, even a highly effective intervention is unlikely to significantly reduce the recidivism rates if those rates are already very low. Undoubtedly, another source of difficulty is the extensive developmental change that occurs during adolescence. Adolescents experience the onset of sexual impulses and the intensification of other appetitive impulses, undergo tremendous changes in social reasoning and susceptibility to social influences, and develop a greater capacity for impulse control and mature social reasoning (Sisk \& Foster, 2004; Steinberg, 2004, 2010; Steinberg, Albert, Cauffman, Banich, Graham, \& Woolard, 2008; Steinberg, \& Monahan, 2007). Thus, risk-taking and inappropriate social behavior are likely to be unstable in adolescence and hence more difficult to predict. Moreover, adolescents who engage in sexual offending behavior constitute a heterogeneous population (Worling, 2001) and the dynamics that produce sexually inappropriate behavior are likely to be diverse and combine in highly individualized ways. Additionally, risk factors may be developmentally sensitive, requiring an age-graded approach to risk assessment (Quinsey, Skilling, Lalumière, \& Craig, 2004; Sampson \& Laub, 1997).

For these reasons, the accurate identification of high risk youth has been elusive. Even among the sexual recidivism risk instruments that have some support of predictive validity, the support appears to be fueled in large part by the correct identification of non-recidivists, who comprise the majority of all evaluation samples. Thus, fewer than half of youth identified as "high risk" to sexually reoffend actually do so (e.g., Worling, Bookalam, \& Litteljohn, 2012). Failure to correctly identify high-risk youth also extends to civil commitment evaluation procedures and registration and notification evaluation procedures, as described below.

\section{口 Civil Commitment}

To our knowledge just one publication rigorously evaluates and fails to support the accuracy of a civil commitment evaluation process designed to identify juvenile sexually violent predators. Caldwell (2013) examined the recidivism rates of youth who met and did not meet one state's commitment criteria. All but three of the 54 youth who met criteria were nevertheless released to the community, as were all of the 144 youth who were eligible for commitment but did not meet criteria. Results of recidivism analyses indicated that, across approximately 5 years of follow-up, youth who met commitmen criteria were significantly less likely to be charged with subsequent offenses (of any kind) than youth who did not meet criteria, and groups did not differ significantly with respect to charges for violent or sexual offenses. Results did not change appreciably when the three committed youth were included in the analyses with the assumption that each would have committed a sexual offense if released. If youth selected for commitment as sexually violent predators are not, in fact, at any higher risk of recidivism than youth not selected, then including youth in SVP screening procedures and subjecting them to civil commitment does not improve community safety (Caldwell, 2013).

Even with poor detection of high risk youth, is it still possible that the treatment received by civilly commitment youth reduces their recidivism risk? We think not. Even if civil commitment was focused on high-risk juveniles, there are several reasons to doubt its potential treatment effectiveness. Congregate care is detrimental for adolescent offenders in and of itself (Freundlich \& Avery, 2005) and any positive effects of interventions delivered in artificial settings are less likely to generalize to real-world settings (Frensch \& Cameron, 2002). Further, although not necessarily related to the civ- 
il commitment process, residential, group-based juvenile treatment is likely to over-emphasize individual-level factors that may or may not be related to recidivism (e.g., victim empathy) while neglecting to address important risk and protective factors within the many settings in which youth are embedded (family, peer, school, community). Indeed, the only intervention for youth who have sexually offended that is supported by multiple randomized controlled trials, Multisystemic Therapy (Henggeler, Schoenwald, Borduin, Rowland, \& Cunningham, 2009), is a parent-focused intervention delivered in youths' homes, schools, and other settings (Borduin, Henggeler, Blaske \& Stein, 1990; Borduin, Schaeffer \& Heiblum, 2008; Letourneau et al., 2009; Letourneau et al., in press). With youth who have sexually offended, MST achieves its positive effects by improving caregiver factors (e.g., appropriate discipline) and addressing peer factors (e.g., reducing association with delinquent peers; Henggeler, Letourneau et al., 2009). Effectively treating youth in specialized residential facilities, sometimes far from their homes and communities, seems, therefore, an unlikely proposition.

\section{- The Effects of Registration and Notification}

Caldwell and his colleagues also evaluated the ability of federal and state protocols to identify high risk youth (Caldwell, Ziemke, \& Vitacco, 2008). To do so, they retrospectively assigned Adam Walsh Act tier designations, as well as scores for three state-developed risk assessment protocols, to juvenile sex and nonsex offenders who had been released from a secure treatment facility for an average of nearly six years. Neither the federal tier system nor any of the state protocols significantly predicted any type of recidivism, with one exception: youth evaluated as meeting the federal requirements for registration were significantly less likely to be charged with new violent offenses.

These results were replicated and extended in a study by Batastini and her colleagues (Batastini, Hunt, Present-Koller, \& DeMatteo, 2011) in a study of 112 adjudicated juvenile sexual offenders followed for a two-year period post treatment. Sixty-seven of the participants (62\%) met the criteria for SORNA Tier 3 registration. Youth who met federal registration criteria $(n=67)$ were no more likely to reoffend, sexually or nonsexually, than youth who did not meet registration criteria $(n=41)$. In fact, only 2 youth reoffended with a new sexual offense across the 2-year follow up period. These results indicate that federal and several state protocols not only misidentify most low-risk youth as higher risk, but also (in the case of the federal protocol), misidentify higher risk youth as low risk. Thus, the federal strategy might actually result in increased risk to community safety.

Given the inability of federal and state risk assessment protocols to correctly identify youth at higher risk of recidivism, it should not be surprising that the four research studies evaluating the effects of registration and notification on recidivism fail to find any evidence that these policies reduce juvenile recidivism. For example, using data from South Carolina, Letourneau and colleagues completed two evaluations of that state's juvenile registration and notification policy on sexual and nonsexual recidivism. In the first study (Letourneau \& Armstrong, 2008) 222 registered and nonregistered male youth were matched on year and type of initial sexual offense, age at offense, race, and prior offenses. Recidivism was assessed across an average 4-year follow-up. The sexual offense reconviction rate was less than $1 \%$ (just two events for 222 youth). The nonsexual violent offense reconviction rates did not differ between registered and nonregistered juveniles.

In a second study (Letourneau, Bandyopadhyay, Sinha, \& Armstrong, 2009b), the sexual and nonsexual recidivism rates of registered male youth $(N=574)$ and nonregistered male youth $(N=1,275)$ were compared across an average 9-year follow-up period. Results indicated that registration had no influence on nonsexual violent recidivism. Results also indicated that registration increased the risk of youth being charged but not convicted of new sex offenses, and being charged but not convicted of new nonviolent offenses. The authors concluded that not only does registration fail to reduce recidivism, it also appears to be associated with increased risk of new charges that do not result in new convictions - possibly indicating a surveillance or "scarlet letter" effect for youth subjected to these policies.

Caldwell and Dickinson (2009) compared the recidivism rates of registered $(n=106)$ and unregistered $(N=66)$ juveniles across a 4-year follow-up period. They reported that registration status was unrelated to new sexual or violent charges. Registered youth were significantly less likely to be charged with new non-violent misdemeanor offenses. Follow-up analyses revealed that registered youth were lower risk as evaluated by juvenile risk assessment tools and thus their lower general recidivism rate is attributable to actual risk, versus some deterrent effect of registration.

Registration and notification could still be effective, even in the absence of a recidivism effect, if these policies deterred initial sex crimes. However, the single study that has evaluated this question failed to find any support for a policy effect on general deterrence. Specifically, Letourneau and colleagues (Letourneau, Bandyopadhyay, Armstrong, \& Sinha, 2010) examined more than 3,000 juvenile sex offense cases from 1991 through 2004. Trend analyses modeled the effects of South Carolina's initial registration law (which did not include online registration) and subsequent revision (that permitted online registration of registered youth) on first-time sex offenses. If either the original or amended policy deterred first-time juvenile offenses, then rates of first-time sex crimes should have declined following policy enactment. However, results indicated no significant deterrent effect for either the original or the revised registration policy. Thus, neither the threat of registration nor the threat of notification was associated with deterrence of first-time juvenile sex crimes.

The available evidence indicates that juvenile registration and notification policies are not associated with the intended effect of reduce sexual offending. These policies are, however, associated with several unintended effects. One of these is the unfair targeting of registered youth for unnecessary arrest. As noted above, Letourneau and colleagues (Letourneau et al., 2009b) found that South Carolina's registration policy was associated with increased risk of new charges but not new convictions. This effect was strongest for nonviolent offenses. Specifically, registered youth were significantly more likely than nonregistered youth to be charged with relatively minor, misdemeanor offenses (e.g., public order offenses). While it is possible that the burdens related to registration actually increased youth misbehavior, the authors believed it is more likely that these findings reflected a surveillance effect. That is, youth who are required to register with law enforcement agencies, and who thus become known as "registered sex offenders," are likely to be viewed (inaccurately) as more dangerous than youth with the same history of sex offending but without the registration label. This perception may cause law enforcement agents to arrest registered youth for behaviors that do not trigger the arrest of nonregistered youth, and that ultimately do not result in new convictions. Requiring youth to register multiple times per year with law enforcement therefore has a significant negative consequences and not merely an inconvenience.

A second unintended effect of registration and notification is to reduce the likelihood that youth are held accountable for sexual offenses. Two related studies support this unintended effect. In an initial study, Letourneau and colleagues (Letourneau, Bandyopadhyay, Sinha, \& Armstrong, 2009a) examined the effects of registration and notification on the likelihood that prosecutors would choose to pursue versus drop or dismiss juvenile sex offense charges. Prosecutor decisions and final dispositions were examined for more than 5,500 juvenile sex offense cases across a 15 -year time period. Results indicated that prosecutors were significantly less likely to pursue sex offense charges after policy implementation. Specifically, there was a $41 \%$ decline in prosecution of these cases following implementation of juvenile registration. The authors interpreted this finding as evidence that prosecutors were trying to protect some youth from that state's lifetime registration and notification requirements.

In the second study, Letourneau and colleagues (Letourneau, Armstrong, Bandyopadhyay, \& 
Sinha, 2013) examined the effects of registration and notification on the likelihood that juvenile sex offense charges would be pled down to lesser, nonsex offense charges. Examining data from nearly 3,000 youth initially charged with sex offenses, they identified dramatic and significant increases in plea bargains corresponding with enactment of South Carolina's registration policy. Specifically, there was a $124 \%$ increase in plea bargains leading to nonsex offense charges from the period predating registration to the period following initial enactment of registration, and another $50 \%$ increase in plea bargains following enactment of online registration notification. Thus, even when deciding to pursue juvenile sex offense charges, judicial actors, including prosecutors, defense attorneys, and judges, appear to evidence a protective mindset and permit many youth to plea responsible to charges that will not trigger registration requirements.

The public branding of some youth as registered sex offenders or sexually violent predators is likely to result in a host of other negative collateral consequences to these youth and their family members (Chaffin, 2008). A recent Human Rights Watch report (2013) detailed the results of nearly 300 interviews with people affected by juvenile registration and notification requirements. The collateral consequences attributed to these policies are appalling and included stigma, isolation, shame, and depression. Suicidal ideation was not uncommon and suicide attempts, both completed and not completed, were identified. Reports indicated that youth and their family members had been beaten, shot at, and even murdered. Youth and young adults have been denied access to education, faced frequent moves, and been unable to find or maintain stable employment or housing. Parents, spouses, and even the children of people registered for juvenile offenses, all reported being affected. Many were unable to navigate complicated registration requirements and sustained new, felony-level "failure to register" convictions.

Another publication reported on the issue from the perspective of four mothers whose sons had been required to register after adjudication for offenses committed between the ages of 13-18 (Comartin Kernsmith, \& Miles, 2010). The mothers each reported a strong desire to protect their sons from further harm, but also feeling powerless to help their sons, fearing that new, and even false, allegations might be lodged against their sons. They also described the stigma and shame they and their sons experienced, caused by the public sex offender label and the low self-esteem of their sons. Finally, the mothers reported that they became isolated and that their sons had difficulty finding employment and achieving financial dependence.

Survey research has long documented these types of extra-legal collateral consequences for registered versus unregistered adults (Levenson \& Cotter, 2005; Levenson, D’Amora, \& Hern, 2007; Merca- do, Alvarez, \& Levenson, 2008; Sample \& Streveler, 2003; Tewksbury, 2004, 2005; Tewksbury \& Lees, 2006; Zevitz \& Farkas, 2000), but has not yet done so with youth. However, in an ongoing study (Harris \& Letourneau, 2013) practitioner perspectives are being evaluated regarding the collateral consequences of juvenile registration and notification. A sample of 219 professionals who provide clinical services to juveniles who have sexually offended has completed the survey to date. Respondents rated whether they disagreed, neither agreed nor disagreed, or agreed that specific negative outcomes were more or less likely to occur to registered versus unregistered youth and (separately) to youth subjected to public notification versus youth not so subjected. With respect to the effects of public notification, a majority of respondents agreed that notification was likely to be associated with 27 of 30 negative outcomes. For example, most practitioners agreed that youth subjected to notification would experience more shame and embarrassment (92\%), feel more alone (91\%), and be more afraid for their own safety (89\%). With respect to registration, a majority of respondents agreed that registration was likely to be associated with 20 of 30 negative outcomes. For example, $87 \%$ believed registered youth would have less hope for the future. In the same study, the investigators are also surveying youth who have sexually offended but the current sample size is too small to present even preliminary findings.

\section{- Conclusions}

The accumulated scientific evidence to date has demonstrated that, when applied to juveniles, sex offender registration and notification and civil commitment laws fail to achieve their stated goal of improving community safety. They fail for several reasons. First, statutory schemes fail to identify youth who are at high risk for sexual recidivism. There is some evidence that they may identify youth who are at lower overall risk for criminal behavior. Second, these policies appear to have no deterrent effect, either on the youth subject to them or on potential future juvenile sexual offenders. Here again, there is some evidence that these laws may actually increase the risk of arrest or offending in some circumstances. Third, these policies appear to reduce the likelihood that juvenile sexual offenders will be fully adjudicated for a sexual offense, resulting in a reduced likelihood that these youth will receive sex offender treatment services. Fourth, these policies have a wide array of damaging collateral effects. The juveniles subject to them face significant obstacles to their successful reintegration into a productive conventional lifestyle. However, what is often overlooked is the fact that the sex offender's employer, cohabitants, neighborhood, and school are often effectively "registered" along with the sex offender in that the addresses of registrants' housing, employers, and schools are often listed on the registry. The collateral damage to those who associate with a registered sex offender has only recently been the subject of systematic study (Human Rights Watch, 2013), which, as noted earlier, identified ongoing and serious negative consequences attributed to public registration.

In addition, these policies carry with them considerable opportunity costs. Maintaining a registration and community notification system is a costly project that will likely increase in cost as the census of those subject to registration grows. Similarly, the cost of indefinite civil commitment of a young sex offender is staggering. In most states, state-of-theart treatment services with demonstrated effectiveness could be provided to scores of youth and their families for less cost than these demonstrated ineffective and counter-productive programs.

Although the existing research is remarkably consistent in finding these policies ineffective, this should not be taken as an indication that further research has nothing to offer. Specifically, additional research into the collateral consequences of these laws will help to fashion future laws that minimize unintended consequences to juvenile offenders, their families, and members of the community. In addition, more detailed costs-benefits analyses will enable policy makers to fashion more cost-effective alternatives.

Perhaps the most striking aspect of these policies is the degree to which they rest on false assumptions about the persistence and intractability of juvenile sexual misconduct. Sexual violence remains among the most serious social problems in this and most western countries. However, there are few serious adolescent behavioral problems that have proven to be more responsive to treatment and maturation. Further, the extant research into what aspects of adolescent development are most relevant to the development of appropriate sexual behavior, and how best to foster and enhance adaptive sexual behavior, remains in its infancy. Similarly, effective treatment methods have been identified, but much more study is needed to develop methods that are flexible and effective with a variety of youth, and that can be delivered most efficiently, while assuring community safety to the maximum extent possible.

\section{- Policy Recommendations}

A fundamental characteristic of the policies discussed is the exercise of society's power to enforce convention, through the identification, supervision, and exclusion of those who are identified as abnormal. Indeed, the power of society to establish and enforce the parameters of convention is fundamental to any well-ordered and civil society. Nearly all societies regulate the sexual behavior of adolescents in some way, and the exclusion of sexual violence and coercion is an important sign post of a modern just and egalitarian society.

However, the policies described here rely heavily on the expulsion of out-group "others" from con- 
ventional society. In many aspects, these policies appear to enact a modern version of the "stultifera navis" (ship of fools), discussed by the French philosopher Michel Foucault (1965), in which Renaissance era villages would place their unwanted citizens on barges that took them downstream, expelled and forgotten by the "normal" social order of the village. The difficulty of this approach is that members of a modern society cannot simply be shipped away. Society instead retains the costs and consequences of policies designed to subject individuals to constant observation or expulsion.

Fortunately, society also employs mechanisms to enforce convention that serve the purpose of reintegrating those who violate social norms. In the area of juvenile sexual misconduct, treatment and rehabilitation services have demonstrated a clear value advantage over the policies described here. Policies that promote proven treatment strategies and minimize long-term stigmatization of adolescents who are charged with sexual offenses should be adopted. The resources devoted to juvenile sex offender registration and community notification and civil commitment would be far more effective in improving community safety if they were devoted to effective prevention and treatment strategies.

Of importance, however, even within the framework of existing policies several, relatively minor, improvements may mitigate much of the collateral harm caused by these policies. First, with respect to civil commitment, policies should be altered to ensure that offenses committed by minors do not automatically trigger SVP evaluation. Rather, commitment should be considered only in rare cases where a juvenile offender appears to represent an ongoing (i.e., post-treatment) threat of harm to the community and community supervision of sufficient oversight is unavailable. In such cases, commitment decisions should be thoroughly re-evaluated frequently (e.g., every 6 months). With respect to registration and notification, policies should be altered to specifically exclude minors. Failing that, we recommend that, registration for adolescents should be based on a competent individualized risk assessment, not on the characteristics of the offense. The dynamics of adolescent sexual misconduct are far too varied and influenced by situational factors for any simple offense-based scheme to effectively identify higher risk adolescents. Second, adolescent sex offenders should never be subjected to community notification, and in particular should never be placed on public registries. The majority of the serious collateral harm related to adolescent sex offender registration is due to the public nature of the registry. Third, if adolescents are to be registered at all, it should be for a short term, no longer than age 18 . The existing evidence is that significant maturationally-driven transitions take place in the later teen years, and the risk of sexual recidivism in an adolescent is greatest over the short- term (Caldwell, 2010; Worling \& Curw- en, 2000). Fourth, private registries that maintain and publicize sex offender registry information should be eliminated. These registries commonly ignore the removal of individuals from the official public registry and require removed individuals to pay substantial fees for removal from the private registry. Fifth, placement on a registry should be contingent on treatment: that is, youth who complete competent treatment avoid registration, whereas youth who fail effective services (for

reasons other than inability to pay for treatment) would then face registration. In placing an individual on a registry, the state is indicating that the individual is a risk to the community. If the state has identified an individual as a risk to community safety, it has an obligation to take reasonable steps to ameliorate that risk. For this reason, placement on a registry should entitle the individual to competent treatment and rehabilitation services. It is well documented that registration often disrupts employment and significantly limits the income of those subject to the registry. At the very least, states should guarantee that all registered youth have access to effective treatment, regardless of their ability to pay for those services.

Lastly, all states should have a reasonable process for individuals to be removed from the registry when it is determined that continued registration does not substantially contribute to community safety. The mechanism for this should be similar to the process for removing individuals from involuntary mental health commitments.

There is no question that sexual violence in society demands a concerted and sustained effort from the state, devoted to improving community safety. The research that has emerged over the past decade has identified effective prevention and treatment programs that do just that. Conversely, while possibly well intentioned, the body of research developed over the past decade has shown that sex offender registration and notification and civil commitment policies, when applied to juveniles, are costly and ineffective, and produce serious unintended collateral harm. They clearly require substantial reform, at a minimum. However, it may be far better to abandon approaches that assume juvenile sexual offenders are intractable and must be isolated and monitored for life altogether. Rather, it may be more effective to begin anew, with a foundation on those measures that have proven effective at improving community safety, and that attempt to reintegrate the individual into a healthy and productive conventional lifestyle.

\section{- References}

$127^{\text {th }}$ General Assembly of Ohio. (2007, June 27). Fiscal Note \& Local Impact Statement. BILL: Am.Sub. S.B.10. Columbus, OH: Ohio Legislative Service Commission. Available from the authors.

Aos, S., Lieb, R., Mayfield, J., Miller, M., \& Pennucci, A. (2004). Benefits and costs of prevention and early intervention programs for youth. Olympia: Washington State Institute for Public Policy.
Aos, S., Phipps, P., Barnoski, R., \& Lieb, R. (2001). The comparative costs and benefits of programs to reduce crime (Version 4.0) Olympia, WA: Washington State Institute for Public Policy. Available at www.wsipp.wa.gov/rptfiles/costbenefit.pdf

Batastini, A. B, Hunt, E., Present-Koller, J., \& DeMatteo, D. (2011). Federal standards for community registration of juvenile sex offenders: An evaluation of risk prediction and future implications. Psychology, Public Policy and Law, 17, 451-474.

Borduin, C. M., Henggeler, S.W., Blaske, D. M., \& Stein, R. (1990). Multisystemic treatment of adolescent sexual offenders. International Journal of Offender Therapy and Comparative Criminology, 34, 105-113.

Borduin, C. M., Schaeffer, C. M., \& Heiblum, N. (2008). A randomized clinical trial of multisystemic therapy with juvenile sexual offenders: Effects on youth social ecology and criminal activity. Manuscript submitted for publication.

Caldwell, M. (2013). Accuracy of sexually violent person assessments of juveniles adjudicated for sexual offenses. Sexual Abuse: A Journal of Research and Treatment. Advance online publication. doi 10.1177/1079063213480818.

Caldwell, M. (2010). Study characteristics and recidivism base rates in juvenile sex offender recidivism. International Journal of Offender Therapy and Comparative Criminology, 54, 197-212.

Caldwell, M. F., \& Dickinson, C. (2009). Sex offender registration and recidivism risk in juvenile sexual offenders. Behavioral Sciences and the Law, 27, 941-956.

Caldwell, M., Ziemke, M. H., \& Vitacco, M. J. (2008). An examination of the sex offender registration and notification act as applied to juveniles. Psychology, Public Policy, and Law, 14, 89-114.

Chaffin, M. (2008). Our minds are made up - Don't confuse us with the facts: Commentary on policies concerning children with sexual behavior problems and juvenile sex offenders. Child Maltreatment, 13, 110-121.

Comartin, E. B., Kernsmith, P. D., \& Miles, B. W. (2010). Family experiences of young adult sex offender registration. Journal of Child Sexual Abuse, 19, 204-225.

Dailard, C. (2006). Legislating against arousal: The growing divide between federal policy and teenage sexual behavior. Guttmacher Policy Review, 9(3). Not paginated. Available at www.guttmacher. org/pubs/gpr/09/3/gpr090312.html.

Department of Planning and Budget. (2008, January). 2008 fiscal impact statement. Bill Number: SB590. Document: G:|2008IEFISI Posted\SB590.DOC. Available at http://lis.virginia.gov/cgi-bin/ legp604.exe?081+oth+SB590F122+PDF.

Foucault, M. (1965). Madness and civilization. New York: Random House.

Frensch, K. M., \& Cameron, G. (2002). Treatment of choice or a last resort? A review of residential mental health placements for children and youth. Child \& Youth Care Forum, 31, 307-339.

Freundlich, M., \& Avery, R. J. (2005). Planning for permanency for youth in congregate care. Children and Youth Services Review, 27, 115-134.

Harris, A. J, \& Letourneau, E. J. (2013). Collateral impacts of juvenile sex offender registration and notification: Provider Perspectives. Paper presented at the American Society of Criminology Annual Meeting. Atlanta, GA.

Henggeler, S. W., Letourneau, E. J., Chapman, J. E., Borduin, C. M., Schewe, P. A., \& McCart, M. R., (2009). Mediators of change for multisystemic therapy with juvenile sexual offenders. Journal of Consulting and Clinical Psychology, 77, 451-462. 
Henggeler, S. W., Schoenwald, S. K., Borduin, C. M., Rowland, M. D. \& Cunningham, P. B. (2009). Multisystemic treatment of antisocial behavior in children and adolescents (2nd ed.). New York: Guilford Press.

Human Rights Watch, (2013). Raised on the registry: The irreparable harm of placing children on sex offender registries in the US. Washington, D.C.: Human Rights Watch. Retrieved July 10, 2013 from: http://www.hrw.org/sites/default/files/reports/us0513_ForUpload_1.pdf.

Jenkins, P. (1998). Moral panic: Changing concepts of the child molester in modern America. New Haven, CT: Yale University Press.

Jones, M. (2007, July 22). The case of the juvenile sex offender: Is he a criminal marked forever or a kid whose behavior can be changed? New York Times Magazine, pp. 33-39, 56, 58-59.

LaFond, J. Q. (2005). Preventing sexual violence: How society should cope with sex offenders. Washington, DC: American Psychological Association.

Lave, T. R. (2009). Only yesterday: The rise and fall of Twentieth Century sexual psychopath laws. Louisiana Law Review, 69, 549-591.

Lester, J. L. (2006). Off to Elba: The legitimacy of sex offender residence and employment restrictions. Bepress Legal Series, Working paper 1818. Available at htt://law.bepress.com/expresso/ eps/1818

Letourneau, E. J. \& Armstrong, K. S. (2008). Recidivism rates for registered and nonregistered juvenile sexual offenders. Sexual Abuse: $A$ Journal of Research and Treatment, 20, 393-408.

Letourneau, E. J., Armstrong, K. S., Bandyopadhyay, D., \& Sinha, D. (2013). Sex offender registration and notification policy increases juvenile plea bargains. Sexual Abuse: A Journal of Research and Treatment, 25, 189-207.

Letourneau, E. J., Bandyopadhyay, D., Armstrong, K. S., \& Sinha, D (2010). Do Sex Offender Registration and Notification Requirements Deter Juvenile Sex Crimes? Criminal Justice and Behavior, 37, 553-569.

Letourneau, E. J., Bandyopadhyay, D., Sinha, D., \& Armstrong, K. S. (2009a). The effects of sex offender registration policies on juvenile justice decision making. Sexual Abuse: A Journal of Research and Treatment, 21, 149-165.

Letourneau, E. J., Bandyopadhyay, D., Sinha, D., \& Armstrong, K. S. (2009b). The influence of sex offender registration on juvenile sexual recidivism. Criminal Justice Policy Review, 20, 136-153.

Letourneau, E. J., Henggeler, S. W., Borduin, C. M., Schewe, P. A., McCart, M. R., Chapman, J. E., \& Saldana, L. (2009). Multisystemic therapy for juvenile sexual offenders: 1-year results from a randomized effectiveness trial. Journal of Family Psychology, 23, 89-102.

Letourneau, E. J., Henggeler, S. W., McCart, M. R, Borduin, C. M. Schewe, P. A., \& Armstrong, K. S. (in press). Two-year follow-up of a randomized effectiveness trial evaluating MST for juveniles who sexually offend. Journal of Family Psychology

Letourneau, E. J., \& Levenson, J. S. (2010). Preventing sexual abuse: Community protection policies and practice. In J. Meyers (Ed.), The APSAC handbook on child maltreatment ( $3^{\text {rd }}$ ed, pp 307-322.) Thousand Oaks, CA: Sage.

Levenson, J. S., \& Cotter, L. P. (2005).The effect of Megan's Law on sex offender reintegration. Journal of Contemporary Criminal Justice, 21, 49-66.
Levenson, J., \& D'Amora, D. (2007). Social policies designed to prevent sexual violence: The Emperor's New Clothes? Criminal Justice Policy Review, 18, 168-199.

Levenson, J., \& D’Amora, D., \& Hern, A. L. (2007). Megan's law and its impact on community re-entry for sex offenders. Behavioral Sciences \& the Law, 25, 587-602.

Mercado, C., Alvarez, S., \& Levenson, J. (2008). The impact of specialized sex offender legislation on community re-entry. Sexual Abuse: A Journal of Research \& Treatment, 20, 188-205.

Muncie, J. (2008). The 'punitive turn' in juvenile justice: Cultures of control and rights compliance in Western Europe and the USA. Youth Justice, 8, 107-121.

National District Attorneys Association (2012). Civil commitment of sex offenders (Updated April, 2012). Available at www.ndaa.org/pdf/ Sex\%200ffender\%20Civil\%20Commitment-April\%202012.pdf.

Office of the Legislative Auditor, State of MN (2011, March). Civil commitment of sex offenders. Evaluation report summary. Available at www.auditor.leg.state.mn.us/ped/pedrep/ccsosum.pdf.

Ordover, N. (2003). American eugenics: Race, queer anatomy, and the science of nationalism. Minneapolis, MN: University of Minnesota Press.

Owens-Adair, B. A. (1922). Human sterilization: Its social and legislative aspects. Portland, OR: Metropolitan Press. Available at www. archive.org/details/humansterlizati00owen.

Pitman, N., \& Nguyen, Q. (2011). A snapshot of juvenile sex offender registration and notification laws: A survey of the United States. Philadelphia, PA: Defender Association of Philadelphia. Available at www.pajuvdefenders.org/file/snapshot.pdf.

Quinsey, V. L., Skilling, T. A., Lalumière, M. L., \& Craig, W. M. (2004). Juvenile delinquency: Understanding the origins of individual differences. Washington, DC: American Psychological Association.

Silver, M. G. (2003-2004). Eugenics and compulsory sterilization laws: Providing redress for the victims of a shameful era in United States history. George Washington Law Review, 72, 862-892.

Sample, L. L., \& Streveler, A. J. (2003). Latent consequences of community notification laws. In S. H. Decker, L. F. Alaird \& C. M. Katz (Eds.), Controversies in criminal justice (pp. 353-362). Los Angeles: Roxbury.

Sampson, R. J., \& Laub, J. H. (1997). A life-course theory of cumulative disadvantage and stability of delinquency. In T. P. Thornberry (Ed.), Developmental theories of crime and delinquency (Advances in Criminological Theory, Volume 7, pp. 133-161). New Brunswick, $\mathrm{NJ}$ : Transaction.

Schwartz, B. K. (2011). Preface. In B. K. Schwartz, (Ed.), Handbook of sex offender treatment (p. v.). Kingston, $\mathrm{NJ}$ : Civic Research Institute.

Sisk, C. L. \& Foster, D. L. (2004). The neural basis of puberty and adolescence. Nature Neuroscience, 7, 1040-1047.

Smith, G. (2010, July 4). S.C.'s tab 7.4M for predators. The Post and Courier. Available at www.postandcourier.com/article/20100704/ PCl1602/307049947.

Steinberg, L. (2004). Risk-taking in adolescence: What changes and why? Annals of the New York Academy of Sciences, 1021, 51-58.

Steinberg, L., (2010). A dual systems model of adolescent risk-taking. Developmental Psychobiology, 52, 216-224
Steinberg, L., Albert, D., Cauffman, E., Banich, M., Graham, S., \& Woolard, J. (2008). Age differences in sensation seeking and impulsivity as indexed by behavior and self-report: Evidence for a dual systems model. Developmental Psychology, 44, 1764-1778.

Steinberg, L., \& Monahan, K. C. (2007). Age differences in resistance to peer influence. Developmental Psychology, 43, 1531-1543.

Sutherland, E. H. (1950). The sexual psychopath laws. Journal of Criminal Law and Criminology, 40, 543-554.

Sutherland, K. (2002-2003). From jailbird to jailbait: Age of consent laws and the construction of teenage sexualities. William \& Mary Journal of Women and the Law, 9, 313-349.

Tewksbury, R. (2004). Experiences and attitudes of registered female sex offenders. Federal Probation, 68, 30-34.

Tewksbury, R. (2005). Collateral consequences of sex offender registration. Journal of Contemporary Criminal Justice, 21(1), 67-82.

Tewksbury, R., \& Lees, M. (2006). Consequences of sex offender registration: Collateral consequences and community experiences. Sociological Spectrum, 26, 309-334.

Worling, J.R., (2001). Personality-based typology of adolescent male sexual offenders: Differences in recidivism rates, victim selection characteristics, and personal victimization histories. Sexual Abuse A Journal of Research and Treatment, 13, 149-166.

Worling, J., \& Curwen, T. (2000). Adolescent sexual offender recidivism: Success of specialized treatment and implications for risk prediction. Child Abuse \& Neglect, 24, 965-982

Worling, J. R., Bookalam, D., \& Litteljohn, A. (2012). Prospective validity of the Estimate of Risk of Adolescent Sexual Offense Recidivism (ERASOR). Sexual Abuse: A Journal of Research and Treatment, 24, 203-223.

Worling, J. R., Litteljohn, A., \& Bookalam, D. (2010). 20-year prospec tive follow-up study of specialized treatment for adolescents who offended sexually. Behavioral Sciences and the Law, 28, 46-57.

Zevitz, R. G., \& Farkas, M. A. (2000). Sex offender community notification: Managing high risk criminals or exacting further vengeance? Behavioral Sciences and the Law, 18, 375-391.

Zimring, F., Jennings, W., Piquero, A., \& Hays, S. (2009). Investigating the continuity of sex offending: Evidence from the second Philadelphia birth cohort. Justice Quarterly, 26, 58-76.

\section{Author Contact Information}

\section{Elizabeth J. Letourneau, Ph.D.}

Associate Professor

Department of Mental Health and Director

Moore Center for the Prevention of Child Sexual Abuse Johns Hopkins Bloomberg School of Public Health eletourn@jhsph.edu

Michael F. Caldwell, Psy.D., Lecturer, Department of Psychology University of Wisconsin, Madison Senior Staff Psychologist

Mendota Juvenile Treatment Center mfcaldwell@wisc.edu 